\title{
Meso-scale Modeling of the Drilling of Carbon Fibre Reinforced Plastic: Geometry and Numerical Analysis
}

\author{
Sinan Al-Wandi ${ }^{1, *}$, Wencheng Pan ${ }^{2}$, Songlin Ding ${ }^{1}$, John P.T. Mo ${ }^{1}$ \\ ${ }^{1}$ School of Engineering, RMIT University, Australia \\ ${ }^{2}$ School of Computing and Engineering, The University of Huddersfield, United Kingdom
}

Copyright $\mathrm{O} 2016$ by authors, all rights reserved. Authors agree that this article remains permanently open access under the terms of the Creative Commons Attribution License 4.0 International License

\begin{abstract}
This paper discussed the 3D finite element modeling (FEM) of the drilling of uni-directional Carbon Fibre Reinforced Plastic (CFRP). Most of the real life parts of CFRP are modeled with single layer shell element and can be modeled as composite by assigning a composite property to it. A Meso-Scale (Laminate Level) approach has been developed to extract displacements, overall stiffness behavior, and detailed stresses and strains. The objective of this study is to implement a ply-based modeling technology to model the laminates and to analyze the interaction mechanisms between the drilling tool and material to validate if the meso-scale approach would be the ideal solution to characterize the drilling induced damage. Results show the model has proved its ability to correctly estimate the thrust force and torque.
\end{abstract}

Keywords Finite Element Model, Drilling, Meso-scale, CFRP

\section{Introduction}

The development of accurate and reliable machining process models has received considerable attention from both academic researchers and industry practitioners in recent years. Traditionally, the techniques used in industry are based on past experience, extensive experimentation, and trial-and-error. Such an approach is time consuming, expensive, and lack of a rigorous general scientific knowledge [1]. Alternative approaches are mathematical simulations where numerical methods are applied. Amongst the numerical procedures, the finite element methods (FEMs) are the most frequently used [2], and can be defined as small interconnected geometrical entities connected to other elements through nodes (1D), boundary lines (2D), and boundary surfaces (3D). Finite element methods have the capability to predict the mechanical and thermal behavior of the material and the tool, without spending time and money with experimental work. Therefore, productivity can be improved and costs can be reduced at the same time.

Progressive damage modeling of polymer matrix composites has received a great deal of attention in recent years as predictive capabilities for the complex nonlinear behavior of these materials are sought [3]. Generally, the term meso-scale is used to describe the intermediate level of material description between micro-scale (modeling the composite to the scale of the constituents such as fibre filament and matrix materials) and macro-scale (modeling the composite to the scale of smeared or homogenous shell/solid, with no detailed ply stresses or strains). In general, the micro-scale is computationally demanding scale whereas the meso-scale approach is treated as effective anisotropic materials and is more computationally efficient.

Niezgoda et al [4] proposed a global-local (meso) modeling method in order to reduce the computational effort usually required to analyze composite structures. The number of elements and nodes used in the meso-scale approach was approximately $60 \%$ lower than in the micro-scale model which allowed analyzing a three-dimensional structure made of composite materials with different orientation of the fibres in a reasonable amount of time. Cherniaev et al [5] presented a meso-scale approach to numerical modeling of hypervelocity impact on CFRP. The material was suitable for explicit modeling of laminate structure, including fibre-reinforced layers and resin-rich regions. Results of simulations were verified against experimental data, good correlation with experiments has been revealed in terms of predicted delamination area and qualitative representation of external damage. Stier et al [6] modeled a meso-scale representative volume element (RVE) of a twill weave CFRP ply consisted of the yarn part, and the surrounding matrix region. The material model accounted for different yield strengths in tensile and compressive direction as well as pressure dependence; verification of the meso-model was conducted through experiments. Numerical and experimental results were in good agreement at small deformations (the proposed model is formulated within the framework of small strain assumption), however at large deformations, particularly at 
large shear strains, the results slightly differed. Lubineau et al [7] proposed a pragmatic approach for the description of the degradation of laminated composites under cyclic loading, including the effect of oxidation. It is based on a hybrid micro-scale and meso-scale modeling of the degradation which includes and generalizes (transverse microcracking and induced local delamination) classical micromechanical approaches for static loading, continuous damage mechanics is used for progressive mechanisms on the ply scale, whereas finite fracture mechanics is used for discrete mechanisms, through minimum cracking surfaces introduced a priori. The results obtained are promising but further research remains necessary for the model to become completely quantitative and predictive.

This paper introduced the new modeling method of ply-based technology to study a 3D finite element model for explicitly simulating the drilling process to investigate the relative significance between the drilling parameters on thrust force and torque. It was significantly shown that the thrust force and torque increase with the increase of feed rate, which indicates the importance of reducing feed rate to achieve better results with respect to drilling forces.

\section{Model Setup}

\subsection{Meso-scale Modeling}

Meso-scale was first introduced by Panin et al. [8] as an approach of modeling properties (density, young modulus, shear modulus, poisson ratio, etc) and the deformation and failure mechanisms of structural and functional materials at different scale levels, with different loads. In meso-scale continuum mechanics size matters, as plastic flow processes in crystalline solids are inherently size dependent over a scale that ranges from a fraction of a micrometer to $100 \mathrm{~mm}$. Such formulations are intermediate between a direct atomistic and an unstructured continuum description of deformation processes [9].

As pointed out by Mishnaevsky [10], the following scale levels are applied in the analysis of material behavior:

- Macro-scale (or a specimen scale), of the order of more than $1 \mathrm{~mm}$. Material behavior at this scale level is analyzed using continuum mechanics methods.

- Micro- and meso-scale (or a microstructure scale), between $1 \mu \mathrm{m}$ and $1 \mathrm{~mm}$. Material behavior at this scale level falls into the area of materials science, and is analyzed using methods of both physics and mechanics of materials, including micromechanics and fracture mechanics.
- Nano- and atomistic scales, less than $1 \mu \mathrm{m}$. Material behavior at this scale level falls into the area of the physics of materials.

\subsection{Ply-based Modeling}

Zone-based models and ply-based models are commonly employed to create composite models. Zone-based models discretize the composite into zones of effective properties, each zone is aligned a material property based on the ply-stacking and fabric deformation. Ply-based models are used to model each ply in composite and material properties and local orientations are assigned to each ply [11].

In this paper, ply-based modeling was applied, as it's more realistic than a zone-based concept, because ply-based means manufacturing-based. In the ply based concept it is simple to add or delete plies at any location.

Fig. 1 shows a simple plate made by four plies. Each ply has different size and orientation, particularly layer \#4 is diagonally oriented. In a zone-based approach the plate has to be divided into 8 zones with different thickness and different fibre direction across the thickness [12], a ply-based approach only requires four plies to capture the behavior of the structure.

\subsection{Finite Element Setup}

Ply-based 3D Lagrangian formulation finite element (FE) model of CFRP composite was developed using ANSYS-EXPLICIT software, and shell181 type of uni-directional CFRP composite laminate was used in the FE analysis as shown in Fig. 2.

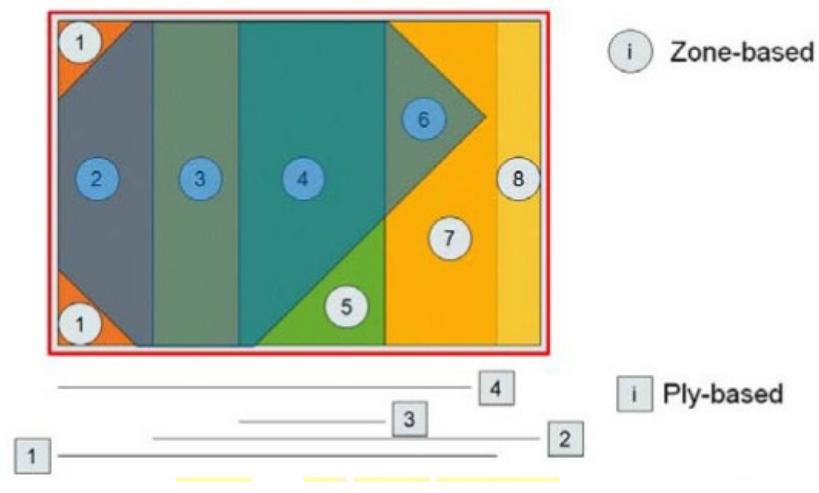

Figure 1. Zone-based vs Ply-based modeling

The boundary conditions were enforced on the workpiece to enable simulation process, as it was fixed from the sides from moving $(\mathrm{ux}=\mathrm{uy}=\mathrm{uz}=0)$. 


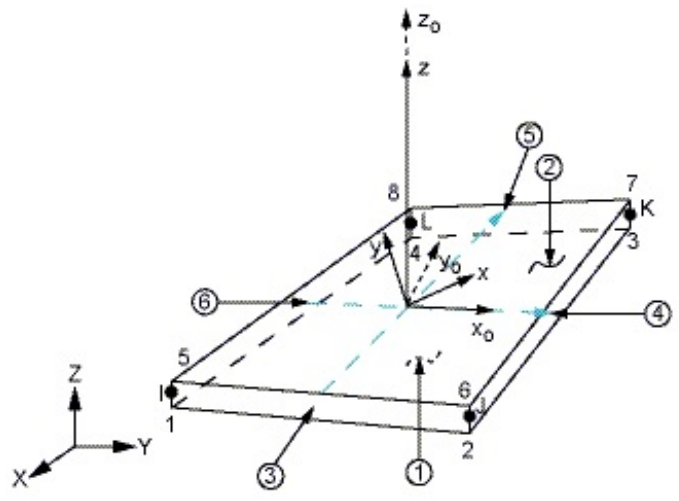

(a)

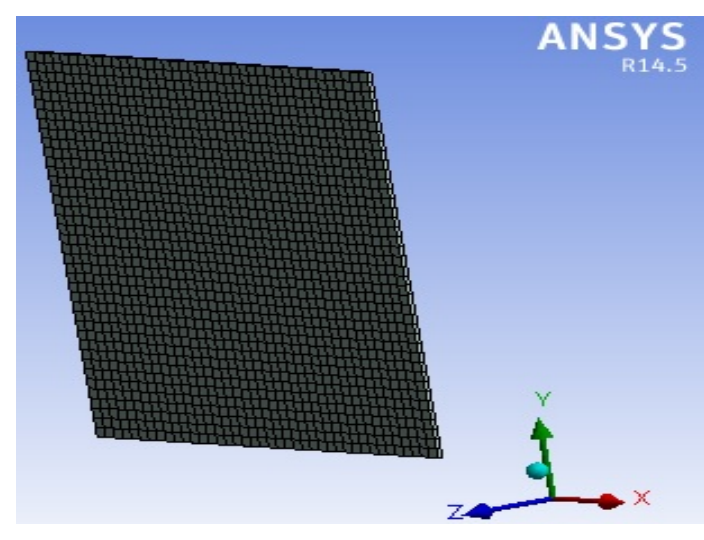

(b)

Figure 2. (a) A schematic illustration of shell181 (b) FE mesh of laminate

Table 1. Mechanical properties of unidirectional VTM264 laminate.

\begin{tabular}{|c|c|c|c|c|c|c|c|c|c|}
\hline E11 & E22 & E33 & v12 & v13 & v23 & G12 & G13 & G23 & $\begin{array}{c}\text { CURED PLY } \\
\text { THICKNESS }\end{array}$ \\
\hline $117 \mathrm{GPa}$ & $7.47 \mathrm{GPa}$ & $7.47 \mathrm{GPa}$ & 0.33 & 0.02 & 0.33 & $4.07 \mathrm{GPa}$ & $4.07 \mathrm{GPa}$ & $2.31 \mathrm{GPa}$ & $0.2 \mathrm{~mm}$ \\
\hline
\end{tabular}

\section{Material Modeling}

A meso-scale modeling approach was used for different components of composite laminate. The material model used for the workpiece was orthotropic homogeneous elastic assigned according to the fibre orientation through a defined local coordinate system. Table 1 shows the material properties of VTM264 [13], which comes in prepregs and available in a wide range of reinforcing fabrics and unidirectional tapes, it features outstanding vacuum-only processing capability for the wildest scope of reinforcement formats, flexible curing capability, free standing postcure capability, excellent glass transition temperature $\mathrm{Tg}$ development, and suitable for full impregnation of light and medium weight unidirectional and fabric reinforcements.

\subsection{Constitutive Material Model of Unidirectional CFRP}

Intralaminar and interlaminar damage mechanisms are the basis of fracture process of composites which include fibre breakage, matrix cracking and delamination. The orthotropic material model for shell layers can be expressed as in-plane stress-strain relationship [14]:

$$
\sigma_{i}=C_{i j} \in_{j}
$$

By setting:

$$
\sigma_{3}=0 \quad \tau_{23}=0 \text { and } \tau_{31}=0
$$

The stress-strain relation in terms of reduced stiffness is:

$$
\left[\begin{array}{c}
\sigma_{1} \\
\sigma_{2} \\
\tau_{12}
\end{array}\right]=\left[\begin{array}{ccc}
Q_{11} & Q_{12} & 0 \\
Q_{12} & Q_{22} & 0 \\
0 & 0 & Q_{66}
\end{array}\right]\left[\begin{array}{c}
\epsilon_{1} \\
\epsilon_{2} \\
\gamma_{12}
\end{array}\right]
$$

Whereas in terms of engineering terms:

$$
\begin{gathered}
Q_{11}=\frac{E_{1}}{1-v_{12} v_{21}} \\
Q_{22}=\frac{E_{2}}{1-v_{12} v_{21}} \\
Q_{12}=\frac{v_{12} E_{2}}{1-v_{12} v_{21}}=\frac{v_{21} E_{1}}{1-v_{12} v_{21}} \\
Q_{66}=G_{12}
\end{gathered}
$$

The stress-strain relationship becomes:

$$
\left[\begin{array}{l}
\sigma_{11} \\
\sigma_{22} \\
\tau_{12}
\end{array}\right]=\left[\begin{array}{ccc}
\frac{E_{1}}{1-v_{12} v_{21}} & \frac{v_{21} E_{1}}{1-v_{12} v_{21}} & 0 \\
\frac{v_{12} E_{2}}{1-v_{12} v_{21}} & \frac{E_{2}}{1-v_{12} v_{21}} & 0 \\
0 & 0 & G_{12}
\end{array}\right]\left[\begin{array}{l}
\epsilon_{11} \\
\epsilon_{22} \\
\gamma_{12}
\end{array}\right]
$$

Where: $\sigma$ normal stress; $\in$ normal strain; $\tau$ shear stress; $\gamma$ shear strain; $E$ modulus of elasticity; $C$ stiffness tensor; $G$ shear modulus; $v$ poisson's ratio; and $Q$ reduced stiffness.

\subsection{Interlaminar Normal Stresses and Shear Stresses}

In the analysis of layered composite structures, shell elements are widely used to keep the computational effort reasonable. In-plane stresses and even transverse shear stresses can be predicted with good accuracy using shells based on the first-order shear deformation theory (FSDT). As shown in Fig. 3, using a cylindrical coordinate system for describing an arbitrary doubly curved shell is the basis for computation of interlaminar normal stresses (INS). 


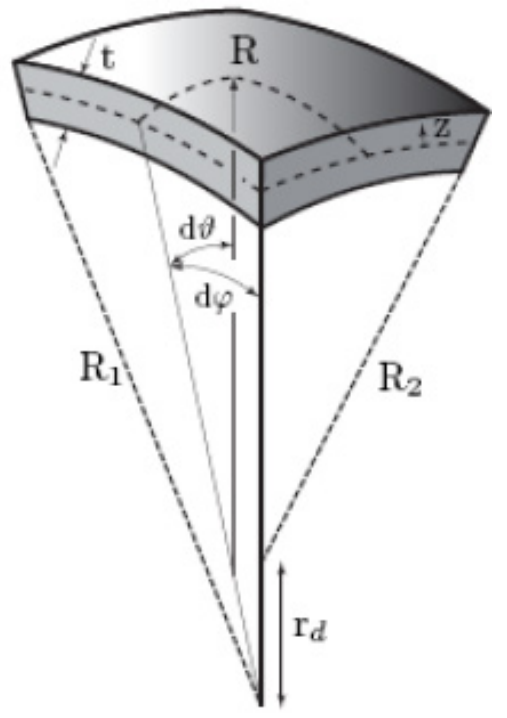

Figure 3. Doubly Curved FE Geometry [15]

The differential equation of the through-the-thickness displacement is:

$$
\begin{gathered}
0=w_{, r r}+w_{, r}\left(\frac{1}{r}+\frac{1}{r+r_{d}}\right)+w\left(\frac{\hat{C}_{13}+\hat{C}_{23}-2 \hat{C}_{12}}{r\left(r+r_{d}\right)}-\frac{\hat{C}_{11}}{r^{2}}-\right. \\
\left.\frac{\hat{C}_{22}}{\left(r+r_{d}\right)^{2}}\right)+P \\
\hat{C}_{i j}=\frac{\bar{C}_{i j}}{\bar{C}_{33}} \text { and } \mathrm{P} \text { is } \\
P=u_{, \varphi}\left(\frac{\hat{C}_{13}-\hat{C}_{12}}{r\left(r+r_{d}\right)}-\frac{\hat{C}_{11}}{r^{2}}\right)+u_{, \varphi r} \frac{\hat{C}_{13}}{r}+v_{\vartheta}\left(\frac{\hat{C}_{23}-\hat{C}_{12}}{r\left(r+r_{d}\right)}-\right. \\
\left.\frac{\hat{C}_{22}}{\left(r+r_{d}\right)^{2}}\right)+v_{, \vartheta r} \frac{\hat{C}_{23}}{r+r_{d}}+\epsilon_{i}^{F}\left(\frac{\hat{C}_{1 i}-\hat{C}_{3 i}}{r}+\frac{\hat{C}_{2 i}-\hat{C}_{3 i}}{r+r_{d}}\right)
\end{gathered}
$$

Where:

$\bar{C}_{\mathrm{ij}}$ are the components of the 3 -dimensional stiffness matrix expressed in reference coordinates, $P$ is the particular part of the differential equation, $u, v, w$ are displacements in the cylindrical coordinate system, $r$ radial ordinate, $r_{d}$ radius difference, $\varphi$ second coordinate of the cylindrical coordinate system, $\vartheta$ third coordinate of the modified cylindrical coordinate system.

$$
r=R_{1}+z, r_{d}=R_{2}-R_{1} \text { and } z=\left[-\frac{t}{2}, \frac{t}{2}\right]
$$

\subsection{Constitutive Damage Initiation and Evolution}

Different failure criteria has been formulated and implemented in finite element analysis of CFRP to predict the damage initiation and evolution. Failure means that one of the stress components reaches the yield stress, and then damage occurrences and progressive failure are observed. Damage can progress in different directions around the weakest element in the model. Usually "Matrix Cracking" is the first damage process to take place since the matrix has the lowest stress to failure [16]. Plates and panels are easily subjected to in-plane multiaxial stress states during service and, depending on the stacking sequence, the in-plane shear stress may play a significant role in the failure. Failure criteria can be grouped into two main groups [17]:

- Failure criteria neglecting interactions between different stress components.

- Failure criteria considering interactions between different stress components.

The first group of failure criteria is sometimes referred to independent failure criteria whilst the second group is referred to polynomial failure criteria.

The maximum stress criteria and the maximum strain criteria are examples of the independent failure criteria. In these criteria, there isn't any dependence between the stress/strain components. This means a component in the longitudinal direction does not affect the component in the transverse direction or stacking direction. Polynomial maximum stress criterion, Polynomial maximum strain criterion, Tsai, Tsai-Hill, Tsai-Azzi, Hoffman, Tsai-Wu and Hashin criteria are the examples of the polynomial failure criteria. In all these criteria, there is dependence between the components in each direction $[18,19]$.

Hashin damage mechanism and failure criterion for the composite material was defined in the FE simulation process to simulate the damage process of matrix and fibre, the failure criterion takes into account the interaction between the four failure modes and therefore chosen in the finite element analysis.

Tensile Fibre Mode

$$
\left(\frac{\sigma_{11}}{\sigma_{11 t}^{f}}\right)^{2}+\left(\frac{\sigma_{12}}{\tau_{12}^{f}}\right)^{2}=1 \quad \sigma_{11>0}
$$

Compressive Fibre Mode

$$
\left(\frac{\sigma_{11}}{\sigma_{11 \mathrm{c}}^{\mathrm{f}}}\right)^{2}=1 \quad \sigma_{11 \leq 0}
$$

Tensile Matrix Mode

$$
\left(\frac{\sigma_{22}}{\sigma_{22 t}^{f}}\right)^{2}+\left(\frac{\sigma_{12}}{\tau_{12}^{f}}\right)^{2}=1 \quad \sigma_{22>0}
$$

Compressive Matrix Mode

$$
\left(\frac{\sigma_{22}}{2 \tau_{12}^{f}}\right)^{2}+\left[\left(\frac{\sigma_{22 c}^{f}}{2 \tau_{12}^{f}}\right)^{2}-1\right]\left(\frac{\sigma_{22}}{\sigma_{22 c}^{f}}\right)+\left(\frac{\tau_{12}}{\tau_{12}^{f}}\right)^{2}=1 \quad \sigma_{22 \leq 0}
$$

Where Hashin's criteria have been fulfilled in any mode damage will be initiated.

Without damage initiation criteria, the damage evolution law has no effect on the material. The damage evolution law defines the way a material degrades following the initiation of damage. The stiffness reduction takes a value of 0 to 1 , where 0 is no damage and 1 is completely damaged.

The damage evolution law variable in the post-damage initiation phase can also be based on the fracture energy dissipated during the damage process, $G \mathrm{c}$.

The damage variable can be defined from the equation below:

$$
D=\frac{\delta_{m}^{f}\left(\delta_{m}^{\max }-\delta_{m}^{0}\right)}{\delta_{m}^{\max }\left(\delta_{m}^{f}-\delta_{m}^{0}\right)}
$$


Where: $\delta_{m}^{f}$ is the mixed-mode displacement at complete failure, $\delta_{m}^{\max }$ refers to the maximum value of the mixed-mode displacement; $\delta_{m}^{0}$ is the effective displacement at the damage initiation.

The failure displacement can be calculated as follows:

$$
\delta_{m}^{f}=2 G c / \sigma_{m}^{0}
$$

\section{Results and Discussion}

The resultant workpiece model was a uni-directional CFRP composite laminate with stack sequence of $[(0 / 90) 2] \mathrm{s}$ used in the FE analysis. The dimension of the sample is $20 \mathrm{~mm} \times 20 \mathrm{~mm} \times 1.6 \mathrm{~mm}$ which consisted of 8 plies, as shown in Fig. 4. The thickness of each ply was $0.2 \mathrm{~mm}$. The workpiece was meshed with shell181 four node linear quadrilateral elements. The mesh was refinement in the drilling area with $200 \mu \mathrm{m}$ elements, total number of elements used was 4,205.
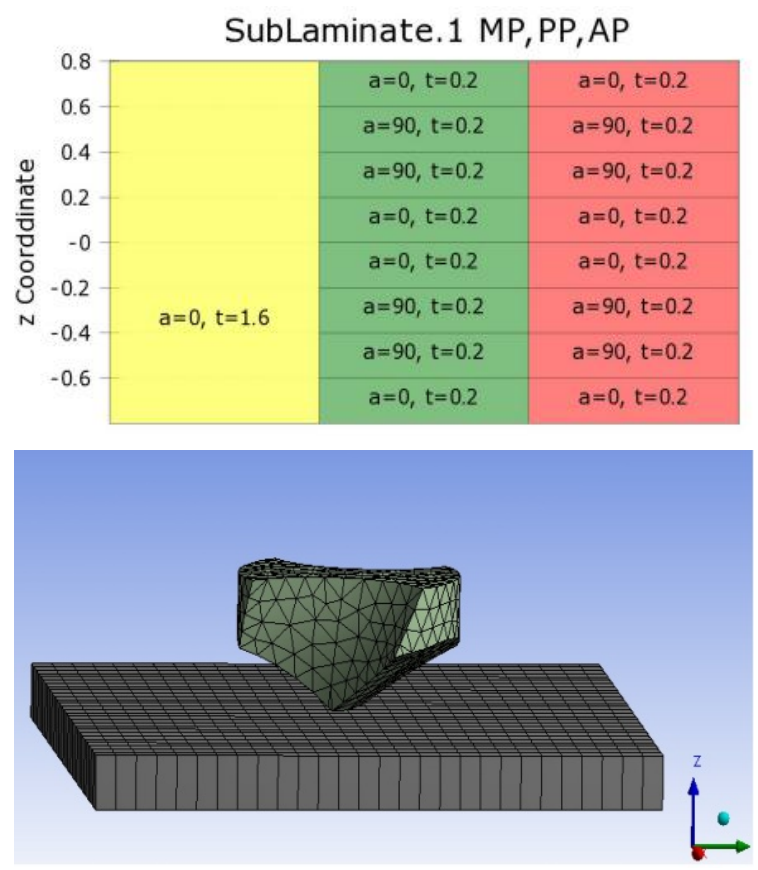

Figure 4. Finite element model of VTM264 CFRP Laminate \&PCD twist drill
The simulation of the drilling process has generated thrust force and torque as shown in Fig. 5a and Fig. 5b. The data was validated with drilling experiments using spindle speed of $5000 \mathrm{rpm}$ and feed rate of $500 \mathrm{~mm} / \mathrm{min}$ shown in Fig 6a and Fig 6b.

Experiment results show the average thrust force is 123.3 $\mathrm{N}$ whereas the $\mathrm{FE}$ result shows $118 \mathrm{~N}$, the experiment torque is $0.39 \mathrm{~N} . \mathrm{m}$ and FE torque result is $0.36 \mathrm{~N} . \mathrm{m}$. Table 2 shows the accuracy between the experiment and the FE simulation results are very close which indicates the FE model is considered accurate.

Table 2. Experimental and FEA force and torque measurements for spindle speed $5000 \mathrm{rpm}$ and feed rate $500 \mathrm{~mm} / \mathrm{min}$.

\begin{tabular}{|c|c|c|c|c|c|c|}
\hline $\begin{array}{c}\text { Drill } \\
\text { Type }\end{array}$ & \multicolumn{2}{|c|}{ Experimental } & \multicolumn{2}{c|}{ FEA } & \multicolumn{2}{c|}{$\%$ Errors } \\
\hline & $\begin{array}{c}\text { Thrust } \\
\text { Force } \\
(\mathrm{N})\end{array}$ & $\begin{array}{c}\text { Torque } \\
(\mathrm{N} . \mathrm{m})\end{array}$ & $\begin{array}{c}\text { Thrust } \\
\text { Force } \\
(\mathrm{N})\end{array}$ & $\begin{array}{c}\text { Torque } \\
(\mathrm{N} . \mathrm{m})\end{array}$ & $\begin{array}{c}\text { Thrust } \\
\text { Force } \\
(\mathrm{N})\end{array}$ & $\begin{array}{c}\text { Torque } \\
(\mathrm{N} . \mathrm{m})\end{array}$ \\
\hline $\begin{array}{c}\text { PCD } \\
\text { Twist } \\
\text { Drill }\end{array}$ & 123.3 & 0.39 & 118 & 0.36 & 4.49 & 8.33 \\
\hline
\end{tabular}

Ply-based composite model preparation and definition of layup can be shared from existing composite layup and can be updated faster when product design changes are required. While there are manufacturing effects that need to be considered when laying up the laminates such as draping (the avoidance of kinking when wrapping material around curved shapes), as shown in Fig. 7, the ply application on curved surfaces changes the theoretical fibre orientations and deformation occurs with the in-plane shear and up to certain deformation level and it's important to know how big this effect can be if it's considered. Ply-based modeling allows evaluating the draped fibre directions with angles can be visualized and are considered in all analysis resulting in more accurate evaluations.

Hence the need for draping simulation is twofold. Firstly, the manufacturability of the composite product can be assessed, areas where the reinforcement cannot follow the surface are indicated and hence measures can be taken in design to avoid this. Secondly, the draping simulation gives the actual fibre orientations at any location in the model. This information is needed for accurate finite element analysis of the structure. 


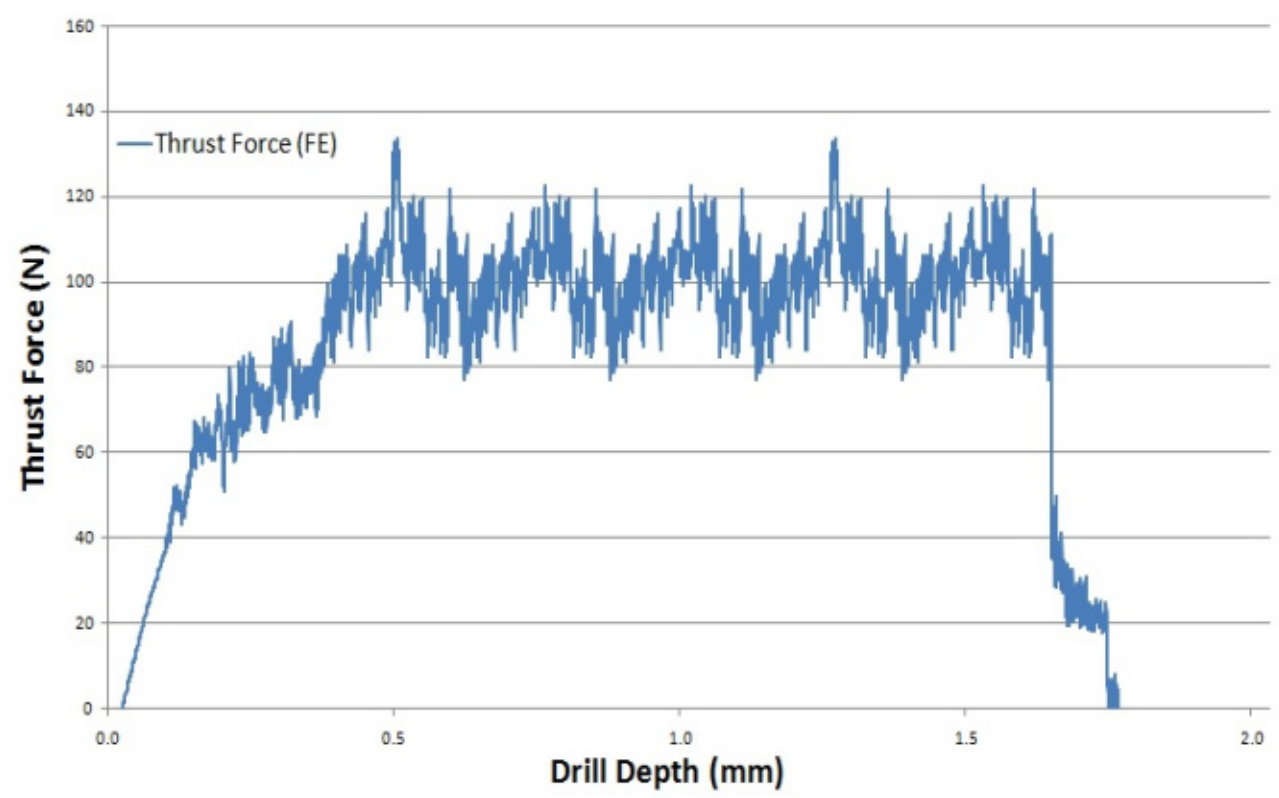

(a)

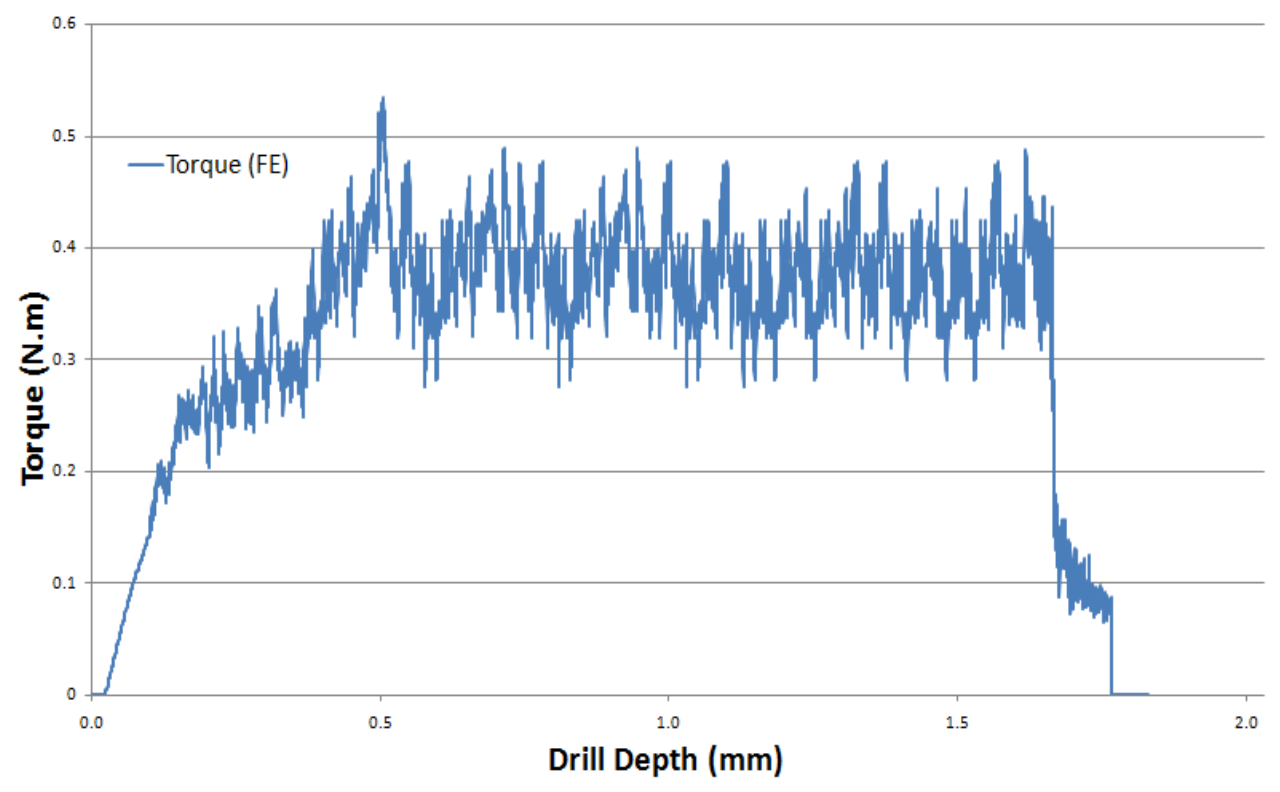

(b)

Figure 5. (a) Simulation result of thrust force (b) Simulation result of torque. 


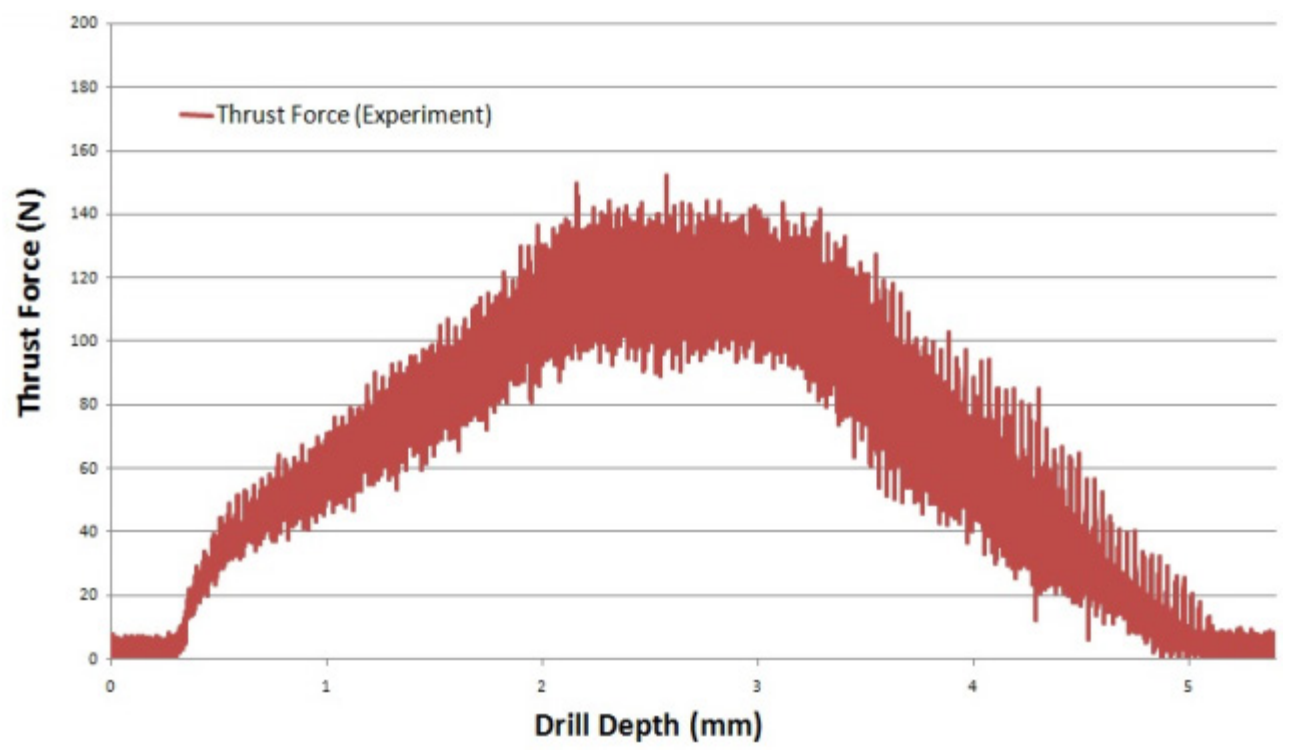

(a)

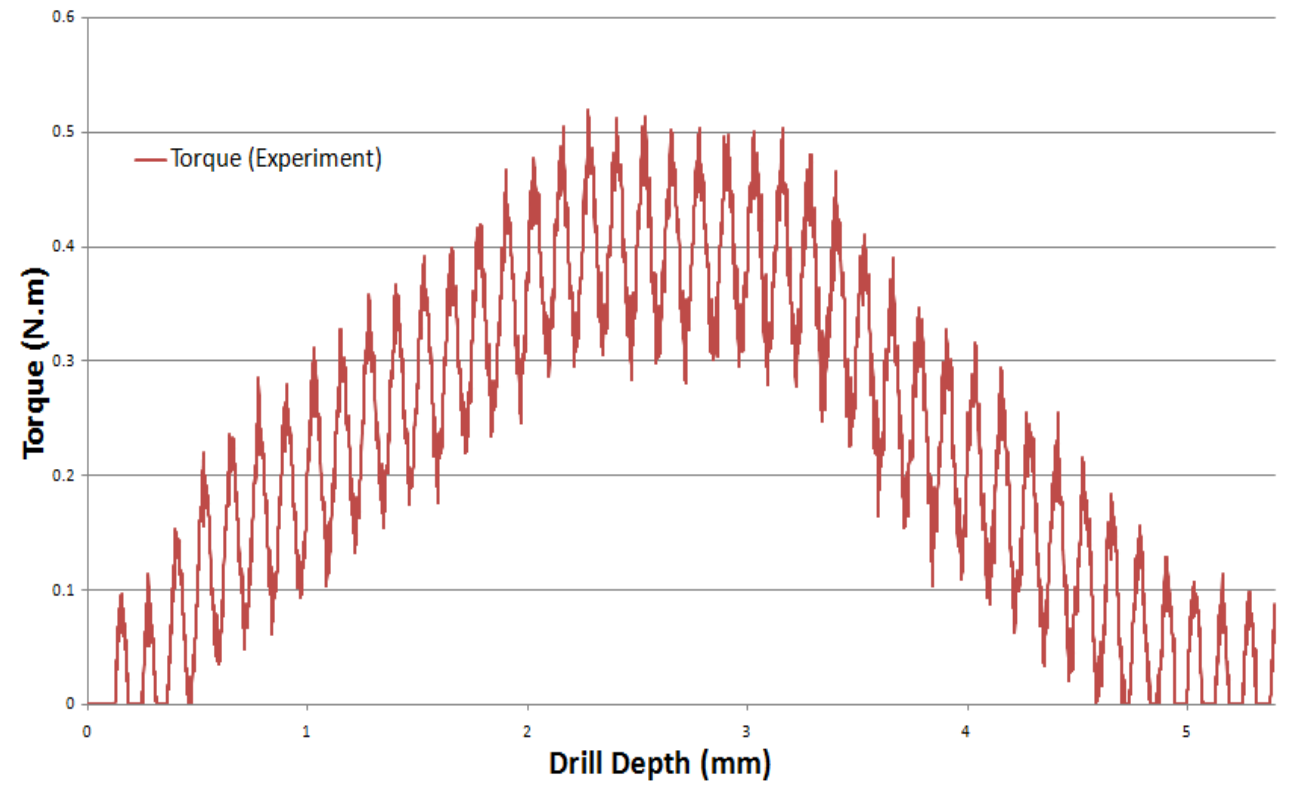

(b)

Figure 6. (a) Experimental result of thrust force (b) Experimental result of torque.

\section{-Fiber Direction}

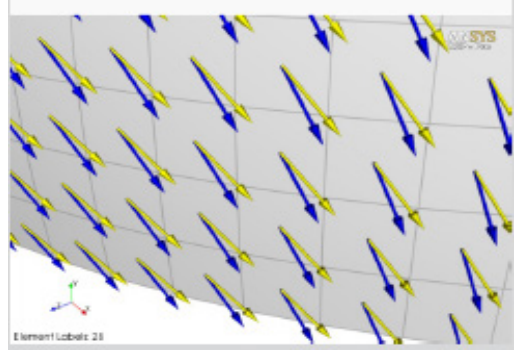

(a)

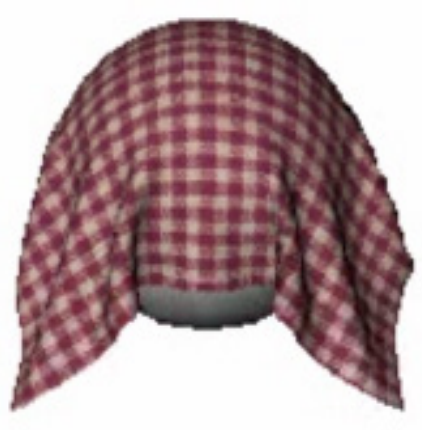

(b)

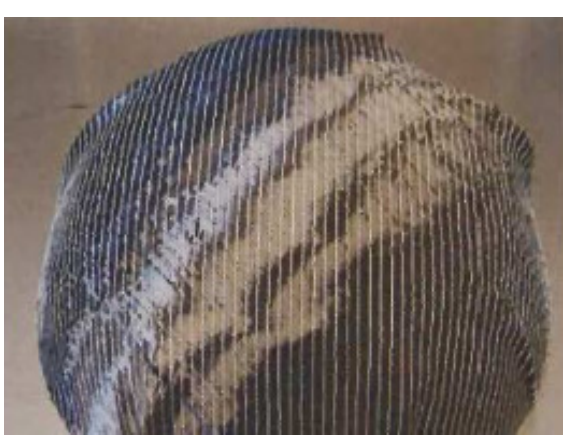

(c)

Figure 7. Draping process and its effect on composite layup. (a) Fibre direction (b) Draping (c) curved shapes. 


\section{Conclusions}

A new model was developed to simulate the drilling of CFRP based on Meso-scale modeling which is a good base material design and for analyzing mechanisms of composite material behavior and its degradation. By using shell elements, it reduces the computational of the simulation process. The model was found to be accurate through validating experiment results which show that the simulation results match the data measured in real drilling tests.

\section{REFERENCES}

[1] Limido, J., et al. (2007). "SPH method applied to high speed cutting modelling." International Journal of Mechanical Sciences 49(7): 898-908.

[2] R Izamshah R.A, J. Mo, S. Ding (2012). Hybrid deflection prediction on machining thin-wall monolithic aerospace component. Proceedings of the Institution of Mechanical Engineers, Part B, Journal of Engineering Manufacture 226(4), 592-605.

[3] Bednarcyk, B. A., et al. (2015). "Meso- and micro-scale modeling of damage in plain weave composites." Composite Structures 121(0): 258-270.

[4] Niezgoda, T. and A. Derewońko (2009). "Multiscale composite FEM modeling." Procedia Engineering 1(1): 209-212.

[5] Cherniaev, A. and I. Telichev (2015). "Meso-scale modeling of hypervelocity impact damage in composite laminates." Composites Part B: Engineering 74(0): 95-103.

[6] Stier, B., et al. (2015). "Comparing experimental results to a numerical meso-scale approach for woven fiber reinforced plastics." Composite Structures 122(0): 553-560.

[7] Lubineau, G., et al. (2006). "Durability of CFRP laminates under thermomechanical loading: A micro-meso damage model." Composites Science and Technology 66(7-8): 983-992.
[8] Panin, V. E., et al. (1998). "Physical mesomechanics of materials." Russian Physics Journal 41(9): 856-884.

[9] Needleman, A. (2000). "Computational mechanics at the mesoscale." Acta Materialia 48(1): 105-124.

[10] Mishnaevsky, L. (2007). Mesoscale Level in the Mechanics of Materials. Computational Mesomechanics of Composites, John Wiley \& Sons, Ltd: 13-36.

[11] Mitchell C. J., et al (2014). "A Discrete Mesoscopic Finite Element Model Used as a Design Tool for Textile Composite Structures." Proceedings of the American Society for Composites: Twenty-ninth Technical Conference on Composite Materials.

[12] Stelzmann U., et al. (2011). "Ply-Based Composite Modeling with the New *ELEMENT SHELL COMPOSITE Keyword." Presented at the $8^{\text {th }}$ European LS-DYNA Users Conference.

[13] Burns LA, Mouritz AP, Pook D, Feih S (2012). "Strength improvement to composite T-joints under bending through bio-inspired design." Composites Part A: Applied Science and Manufacturing 43 (11):1971-1980.

[14] Jones R.M. (1975) "Mechanics of Composite Material" Hemisphere, New York.

[15] Roos, R., et al. (2007). "A post-processing method for interlaminar normal stresses in doubly curved laminates." Composite Structures 81(3): 463-470.

[16] Rakesh, P. K., et al. (2011). "Delamination in Fiber Reinforced Plastics: A Finite Element Approach." Engineering 03(05): 549.

[17] Nali, P. and E. Carrera (2012). "A numerical assessment on two-dimensional failure criteria for composite layered structures." Composites Part B: Engineering 43(2): 280-289.

[18] Isbilir, O. and E. Ghassemieh (2012). "Finite Element Analysis of Drilling of Carbon Fibre Reinforced Composites." Applied Composite Materials 19(3-4): 637-656.

[19] Lapczyk, I. and J. A. Hurtado (2007). "Progressive damage modeling in fiber-reinforced materials." Composites Part A: Applied Science and Manufacturing 38(11): 2333-2341. 